\title{
Correlation of the free radical and antioxidant activities of Eriobotrya Japonica Lindl. with phenolic and flavonoid contents
}

\author{
Ho Young SEON ${ }^{1 *}$, Sangouk SUN ${ }^{1 *}$, Soon-Ho YIM ${ }^{1 *}$ (it)
}

\begin{abstract}
This study was conducted to compare the correlations between antioxidant activity and free radicals. Total Polyphenol and Flavonoid contents were the highest $31.97 \pm 1.29 \mathrm{mg} \mathrm{TAE} / \mathrm{g}$ and $96.1 \pm 0.31 \mathrm{mg}$ CE/g in hot water extract, respectively. FRAP activity was highest at $559.17 \pm 2.69 \mathrm{mg} \mathrm{TE} / \mathrm{g}$ in $60 \% \mathrm{EtOH}$ extract. The RC50 values of DPPH and ABTS radical scavenging activity were lowest at $61.96 \pm 5.01 \mu \mathrm{g} / \mathrm{mL}$ in $80 \% \mathrm{EtOH}, 73.81 \pm 0.16 \mu \mathrm{g} / \mathrm{mL}$ in $60 \% \mathrm{EtOH}$, respectively. The RC50 values of hydrogen peroxide scavenging activity and NO radical scavenging activity were lowest at $265.33 \pm 3.88 \mu \mathrm{g} / \mathrm{mL}$ in $60 \% \mathrm{EtOH}$ and $52.51 \pm 8.54 \mu \mathrm{g} / \mathrm{mL}$ in hot water extract, respectively. The total polyphenol and flavonoid contents had significant correlation with the free radical scavenging ability and electron donating ability. On the other hand, there was confirmed significant correlation of free radical and antioxidant activities.
\end{abstract}

Keywords: Eriobotrya japonica; antioxidant; correlation; ROS; RNS.

Practical Application: Research about antioxidant activities and functional products of E. japonica leaves

\section{Introduction}

Various external environmental factors such as environmental pollutants, ultraviolet rays, smoking, and alcohol intake in modern society are causing the occurrence of Reactive Oxygen Species (ROS) and Reactive Nitrogen Species (RNS), which causes health problems. Active oxygen species such as superoxide anion radical, hydrogen peroxide, and hydroxyl radical etc. are used in the process of oxygen oxidation during respiratory process and are produced through various metabolic processes. It is regulated by an in vivo antioxidant defense system such as SOD, glutathione, catalase and the like present in the human body (Hwang \& Thi, 2014). However, excessively produced ROS damage tissues and cells, inhibit protein breakdown, DNA synthesis, reduce skin elasticity, skin wrinkle formation and cause pigmentation such as spots, freckles, blotch, and skin aging (Halliwell et al., 1992). In addition, RNS refers to nitrogen compounds such as $\mathrm{NO}, \mathrm{NO}_{2}$, and $\mathrm{ONOO}^{-}$can easily diffuse into the cell membrane and react with other free radicals. In particular, $\mathrm{NO}$ combines with $\mathrm{O}^{-}$to produce peroxynitrite (ONOO-), which is highly reactive (Carr et al., 2000) (Figure 1), which induces cytotoxicity by peroxidizing tissue proteins, nucleic acids, phospholipids, and other senile diseases. Oxidative stress of the ROS and RNS can induce a variety of diseases that not only contribute to the aging process, but also degenerative diseases, atherosclerosis, diabetes, hypertension, and cancer, etc. (Chung et al., 2000; Yu, 1996; Rittié \& Fisher, 2002).

Recently, studies on antioxidant substances in order to eliminate ROS and RNS that increase or eliminate antioxidants in the human body have been conducted, and various physiological activity research such as antioxidant and anti-cancer effects of natural products have been widely reported (Choi et al., 2003; Kim et al., 2008).

E. japonica Lindl. is an evergreen tree of the Rosaceae family, and grows extensively in the Middle East, Asia, and Mediterranean coasts, as well as in China and Japan. It is grown mainly in mild climatic conditions such as Jeju, Gyeongnam and Jeonnam in Korea (Park \& Park, 1995; Park \& Kim, 2000). It has been known in traditional medicines that $E$. japonica fruits and leaves are effective for antitussives, expectorant, vomiting, hemoptysis, and diuresis, and are also reported to be effective in relieving breathing and thirst (Eom et al., 2009; Shin et al., 2012; Lee et al., 2016a). The E. japonica leaves contains a large amount of bioactive compounds such as terpenoid-based compounds (ursolic acid, oleanolic acid etc.) and flavonoids (chlorogenic acid, kaempferol etc.) (Nazato et al., 1994; Jung et al., 1999). Recently, E. japonica has been used as a functional food and pharmaceutical products due to its beneficial effects including loquat juice and physicochemical properties (Bae et al., 1998), chemical composition and antioxidant efficacy (Hwang et al., 2010), identification of the content of E. japonica (Kim et al., 2009; Cho et al., 1991; Lee et al., 1996), physiological activity, antioxidant and antibacterial activity, and antimutagenic effects (Jeong et al., 2009; Bae et al., 2002a, b; Park et al., 2008; Lee \& Kim, 2009). According to the study of E. japonica, the analysis of the antioxidant activity and physiologically active ingredient was mostly performed using the areal sections. Moreover, the correlation between physiologically active compounds in E. japonica leaves, and antioxidant activity (ROS, RNS etc.) have not been investigated in previous literature reports. 


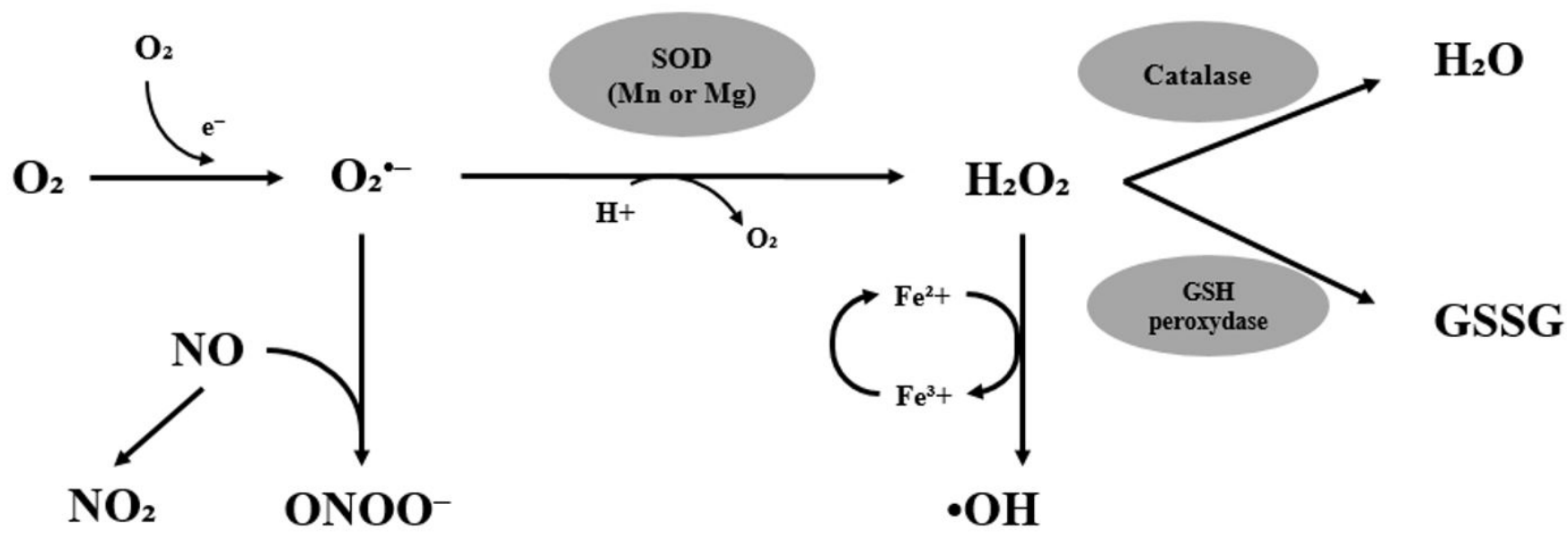

Figure 1. Generation and removal process of reactive oxygen species produced by in vivo

Therefore, this research was carried out on the protective effect of different ethanol extracts of E. japonica against free radicals under in vitro situations. In vitro assays were evaluated on TPC (total phenolic content), TFC (total flavonoid content), DPPH radical scavenging, ABTS radical scavenging, FRAP (ferric reducing antioxidant power), HP (Hydrogen peroxide scavenging), NO (nitric oxide). Further, the free radical scavenging activities were correlated with phytochemical contents of the E. japonica leaves extracts. This is the reason that there is considerable scientific and commercial interest in discovering new antioxidants from natural product sources.

\section{Materials and methods}

\subsection{Plant materials}

The loquat leaves used in this study was purchased from Goheung, Korea's loquat orchard, in September-October 2018 to identify and use the loquat leaves from the Jeonnam Herbal Medicine Agricultural Cooperative. The loquat sample was washed clean and then dried in a dry oven at $80^{\circ} \mathrm{C}$ for $5 \mathrm{~h}$ to be crushed to a diameter of about $1 \mathrm{~cm}$ or less.

\subsection{Chemical and reagents}

Folin-Ciocalteu reagent, ABTS (2,2'-azino-bis-3-ethylbenzothiazoline-6-sulfonic acid), DPPH (1,1-diphenyl-2picrylhydrazyl), tannic acid, catechin, L-ascorbic acid, DAF-2 (4,5-Diamino fluroprusside), Sodium nitroprusside dihydrate, etc. are Sigma-Aldrich Co. (St. Louis, MO, USA) products were used, and other extraction solvents and all reagents used were special reagents. A spectrophotometer (Neogen, Optizen 2120 UV, Sejong, Korea), ELISA reader (Thermo Fisher SCIENTIFIC, Multiskan Sky, KOREA) was used as the instruent.

\subsection{Extraction}

Extraction conditions according to the ethanol concentration were selected through preliminary tests of conditions for various solvent concentrations of E. japonica leaves. The E. japonica leaves were extracted with $10 \mathrm{vol}(\mathrm{v} / \mathrm{w})$ ethanol $(0 \%, 20 \%, 40 \%$, $60 \%, 80 \%, 100 \%$ ) using a heating mantle at $100{ }^{\circ} \mathrm{C}$ for $4 \mathrm{~h}$ and concentrated. The concentrated sample was frozen in a deep freezer at $-70{ }^{\circ} \mathrm{C}$ for $24 \mathrm{~h}$, then lyophilized and stored at $4{ }^{\circ} \mathrm{C}$ for use in the experiment.

\subsection{Determination of total polyphenol contents}

Total polyphenol content analysis was measured by applying the modified method of Folin \& Denis (1912). The sample solution $(0.5 \mathrm{~mL})$ was placed in the EP tube with Folin reagent $(0.5 \mathrm{~mL})$ and $10 \%$ sodium carbonate $(0.5 \mathrm{~mL})$. After incubation for $1 \mathrm{~h}$ at $25^{\circ} \mathrm{C}$, absorbance was measured at $760 \mathrm{~nm}$ using a UV/VIS spectrophotometer (Neogen, Optizen 2120 UV, Sejong, Korea). After creating a standard curve using tannic acid, the polyphenol amount was calculated as the tannic acid equivalent amount, and the equation was calculated as $\mathrm{y}=0.0366 \mathrm{x}-0.0033\left(\mathrm{r}^{2}=0.9933\right)$.

\subsection{Determination of total flavonoid contents}

Total flavonoid content analysis was measured by applying the modified method of Saleh \& Hameed (2008). The sample $(150 \mu \mathrm{L})$ was mixed with $80 \%$ ethanol $(600 \mu \mathrm{L})$ and $5 \%$ sodium nitrite $(45 \mu \mathrm{L})$ and reacted at room temperature for $5 \mathrm{~min}$, after which $10 \%$ aluminium chloride $(45 \mu \mathrm{L})$ was added and left at room temperature for $5 \mathrm{~min} .1 \mathrm{~N} \mathrm{NaOH}$ was mixed with $300 \mu \mathrm{L}$, and absorbance was measured at $510 \mathrm{~nm}$ using a UV/VIS spectrophotometer (Neogen, Optizen 2120 UV, Sejong, Korea). A standard curve was prepared using Catechin to calculate the amount of flavonoids in terms of catechin equivalent, and the equation was calculated as $\mathrm{y}=0.0025 \mathrm{x}+0.0142\left(\mathrm{r}^{2}=0.9992\right)$.

\subsection{Assay for the estimation of free radical}

\section{DPPH radical scavenging activity}

DPPH radical scavenging ability is one of the methods to confirm the electron-donating ability and was measured by applying the modified method of Blois (1958). The sample 
solution $(10 \mu \mathrm{L})$ was placed in 96 well plate with $0.2 \mathrm{mM} \mathrm{DPPH}$ $(190 \mu \mathrm{L})$. After incubation for $0.5 \mathrm{~h}$ at $25^{\circ} \mathrm{C}$, absorbance was measured at $515 \mathrm{~nm}$ using an ELISA reader (Thermo Fisher SCIENTIFIC, Multiskan Sky, KOREA). L-ascorbic acid was used as a positive control. The antioxidant activity was expressed as a percentage in the following manner (Equation 1).

$D P P H$ radical scavenging activity $(\%)=\frac{(A-B)}{A} \times 100$

A: absorbance of control

B: absorbance of test sample

\section{ABTS radical scavenging activity}

ABTS radical scavenging ability is one of the methods to confirm the electron-donating ability and was measured by applying the modified method of Re et al. (1999). 7 mM ABTS and $2.45 \mathrm{mM}$ potassium persulfate were mixed at a ratio of $1: 1$ $(\mathrm{v} / \mathrm{v})$ to react in a darkroom at $25^{\circ} \mathrm{C}$ for 24 hours to generate radicals. Radical stock solution was diluted with distilled water so that the absorbance value at $734 \mathrm{~nm}$ was $0.70 \pm 0.02$. After incubation for $5 \mathrm{~min}$ in a dark room at $25^{\circ} \mathrm{C}$, absorbance was measured at $734 \mathrm{~nm}$ using a UV/VIS spectrophotometer (Neogen, Optizen 2120 UV, Sejong, Korea). L-ascorbic acid was used as a positive control. The antioxidant activity was expressed as a percentage in the following manner (Equation 2).

ABTS radical scavenging activity $(\%)=\frac{(A-B)}{A} \times 100$

A: absorbance of control

B: absorbance of test sample

\subsection{Assay for the estimation of Antioxidant activity}

\section{FRAP assay}

Ferric reducing antioxidant power (FRAP) was measured by modifying the method of Benzie \& Strain (1996). FRAP working solution was prepared by mixing $300 \mathrm{mM}$ sodium acetate buffer (pH 3.6), $10 \mathrm{mM} \mathrm{2,4,6-tripyridyls-triazine} \mathrm{(TPTZ)} \mathrm{and} 20 \mathrm{mM}$ $\mathrm{FeCl}_{3}$ in a 10: 1: 1 ratio. This was used by incubation at $37^{\circ} \mathrm{C}$ for $10 \mathrm{~min}$. FRAP working solution $(1050 \mu \mathrm{L})$ was added to the sample $(35 \mu \mathrm{L})$, reacted at $37^{\circ} \mathrm{C}$ for $30 \mathrm{~min}$, and absorbance at $595 \mathrm{~nm}$ was measured using a UV/VIS spectrophotometer (Neogen, Optizen 2120 UV, Sejong, Korea). A standard curve was created using Trolox, FRAP was calculated as the equivalent amount of Trolox, and the equation was calculated as $\mathrm{y}=0.0014 \mathrm{x}$ $+0.0628\left(r^{2}=0.9933\right)$.

\section{Hydrogen peroxide scavenging activity}

Hydrogen peroxide scavenging activity was applied in Muller (1995) method 2,2-azinobis (3-ethylbenzthiazolin)-6-sulfonic acid (ABTS)-peroxidase system to measure $\mathrm{H} 2 \mathrm{O} 2$ scavenging activity. In 96 well plate, $80 \mu \mathrm{L}$ of sample solution, $20 \mu \mathrm{L}$ of $10 \mathrm{mM}$
$\mathrm{H}_{2} \mathrm{O}_{2}$ and $100 \mu \mathrm{L}$ of $0.1 \mathrm{M}$ phosphate buffer ( $\mathrm{pH}$ 5.0) were added and reacted at $37^{\circ} \mathrm{C}$ for $5 \mathrm{~min}$. Add $30 \mu \mathrm{L}$ of $1.25 \mathrm{mM}$ ABTS and $30 \mu \mathrm{L}$ of $1 \mathrm{U} / \mathrm{mL}$ peroxidase mix. After reacting at $37^{\circ} \mathrm{C}$ for $10 \mathrm{~min}$, absorbance was measured at $405 \mathrm{~nm}$ using an ELISA reader (Thermo Fisher SCIENTIFIC, Multiskan Sky, KOREA).

\section{Nitric oxide scavenging activity}

The scavenging activity of nitric oxide forms a triazolo fluoresceun that emits green fluorescence at an excitation wavelength of $490 \sim 495 \mathrm{~nm}$ by the specific NO indicator DAF-2 trapping NO between its two amino groups. DAF-2 solution was prepared by dissolving $1 \mathrm{mg}$ of DAF- 2 in $0.55 \mathrm{ml}$ of Dimethyl sulfoxide and diluting it again to 400 times (v/v) using $50 \mathrm{mM}$ phosphate buffer ( $\mathrm{pH} 7.4$ ). $10 \mu \mathrm{L}$ of the sample was mixed with $130 \mu \mathrm{L}$ of $50 \mathrm{mM}$ phosphate buffer ( $\mathrm{pH} 7.4$ ), after which $10 \mu \mathrm{L}$ of $40 \mathrm{mM}$ SIN-1 and $50 \mu \mathrm{L}$ of DAF- 2 solution were added. The fluorescence intensity of triazolofluorescein produced by the reaction of DAF-2 and NO for $10 \mathrm{~min}$ at room temperature was measured at excitation $485 \mathrm{~nm}$ and emission $525 \mathrm{~nm}$ using a fluorescence microplate reader (Molecular Devices, Gemini EM, U.S.A).

\subsection{Statistical analysis}

The experimental data of this study were expressed as the mean \pm standard deviation after three repeated experiments. Significant difference tests were performed by one-way variance analysis and Tukey's multiple range test (TMRT) method using SPSS (statistical package for the social sciences, ver. 25) $(\mathrm{p}<0.05)$. Correlation analysis was performed using the Pearson linear correlation method at a significance level of 0.05 .

\section{Results and Discussion}

\subsection{Extraction}

The yield of the plant extract is considered an important factor in the measurement of antioxidant activity, and even if the physiological activity of the extract is excellent, the economic efficiency is insufficient when the yield of the extract is low. The extraction yield is an important part to be considered for various commercialization and industrialization purposes of functional extracts (Ham et al., 2015). Therefore, according to the results of the preliminary test from E. japonica, it was extracted for each ethanol concentration of $20 \%, 40 \%, 60 \%, 80 \%$, and $100 \%$ suitable ingredient for food, medicine, and cosmetics. The ethanol extracts were concentrated under vacuum and the total extraction yields of ethanolic extracts from E. japonica are shown in Table 1. The yield of hot water (20.0\%), 20\% EtOH (14.5\%), and $80 \%$ $\mathrm{EtOH}(14.4 \%)$ was higher than those of $40 \% \mathrm{EtOH}$ (5.2\%), 60\% $\mathrm{EtOH}(9.37 \%)$, and $100 \% \mathrm{EtOH}$ (9.16\%), respectively.

This is presumed to show the difference in extraction yield as a variable of the mixing ratio of water and ethanol for the sample. If the extraction yield is more than $10 \%$, it is known to be economical, so the hot water, $20 \% \mathrm{EtOH}$, and $80 \% \mathrm{EtOH}$ extract are considered as economically high-potential plant materials (Park et al., 2003). 
Table 1. The extraction yield of various solvent extracts obtained from dry weight E. japonica Leaves.

\begin{tabular}{cccc}
\hline Sample & Yields $(\mathrm{wt} \%)^{1)}$ & Polyphenol contents $\left(\mathrm{mg} \mathrm{TAE} / \mathrm{g}^{2}\right)$ & Flavonoid contents $\left(\mathrm{mg} \mathrm{CE} / \mathrm{g}^{3}\right)$ \\
\hline Water & 20.00 & $31.97 \pm 1.29^{4)} \mathrm{c}^{5)}$ & $96.10 \pm 0.31 \mathrm{e}$ \\
$20 \% \mathrm{EtOH}$ & 14.46 & $20.33 \pm 0.02 \mathrm{a}$ & $73.20 \pm 0.20 \mathrm{~b}$ \\
$40 \% \mathrm{EtOH}$ & 5.22 & $26.50 \pm 0.26 \mathrm{~b}$ & $88.69 \pm 0.20 \mathrm{~d}$ \\
$60 \% \mathrm{EtOH}$ & 9.37 & $27.51 \pm 0.71 \mathrm{~b}$ & $88.47 \pm 0.26 \mathrm{~d}$ \\
$80 \% \mathrm{EtOH}$ & 14.44 & $25.92 \pm 1.79 \mathrm{~b}$ & $81.79 \pm 0.16 \mathrm{c}$ \\
$100 \% \mathrm{EtOH}$ & 9.16 & $19.11 \pm 1.06 \mathrm{a}$ & $66.74 \pm 0.16 \mathrm{a}$ \\
\hline
\end{tabular}

${ }^{1)}$ Yield $(\%, w / w)=($ dry weight of extract / weight of dry E. japonica Lindl. $) \times 100 ;{ }^{2)}$ Total Polyphenol analyzed as tannic acid equivalent (TAE) mg/g of extract; ${ }^{3)}$ Total Flavonoid content analyzed as catechin equivalent (CE) $\mathrm{mg} / \mathrm{g}$ of extract; values are the average of triplicates. ${ }^{4)}$ Values are means of triplicate determination \pm S.D; ${ }^{5)}$ Means with different letters (a-e) in the same column are significantly different at $\mathrm{p}<0.05$ (Tukey)

\subsection{Total phenolic and total flavonoid contents}

The phenolic compounds of the representative secondary metabolite from plants are an aromatic compound having a hydroxyl group and are known to be involved in various physiological activities. It is known that the effect on antioxidant activity varies depending on the type or content of the phenolic compound (Liu, 2004; Manach et al., 2005; Ryu et al., 2006). In addition, flavonoids, which are known to inhibit oxidative action in vivo, are important compounds in determining the antioxidant power of natural products and have the ability to scavenge free radicals as the most helpful substances for immune enhancement, and it have been reported to exhibit the ability to scavenge free radicals and inhibit the formation of lipid peroxide (Middleton \& Kandaswami, 1994; Lee \& Kim, 2009; Song et al., 2015).

In this study, the total polyphenol and flavonoid compound contents were measured by tannic acid and catechin, respectively (Table 1). The total polyphenol content was highest in the hot water extract at $31.97 \pm 1.29 \mathrm{mg} \mathrm{TAE} / \mathrm{g}$, followed by $60 \%$ ethanol $(27.51 \pm 0.71)$ and $20 \%$ ethanol extract $(20.33 \pm 0.02)$. The total flavonoid content showed the highest value as $96.10 \pm 0.31 \mathrm{mg}$ $\mathrm{CE} g$ of hot water extract, and it contained total flavonoids in the order of $40 \%$ ethanol $(88.69 \pm 0.20)$ and $60 \%$ ethanol extract $(88.47 \pm 0.26)$.

\subsection{The estimation of free radical}

\section{$D P P H$ radical scavenging}

The DPPH assay is a principle of a stable free radical measures such as vitamin $\mathrm{C}$, tocophenol and aromatic compounds that has been widely used to evaluate the radical scavenging ability of various samples (Yoo et al., 2004). The fee radical scavenging activity evaluated by DPPH was expressed as the $\mathrm{RC}_{50}$ value (the concentration of sample required for scavenging radical by $50 \%$ ). All extract samples showed a high activity of $80 \%$ or higher at concentrations above $200 \mu \mathrm{g} / \mathrm{mL}$ (not show). $\mathrm{RC}_{50}$ values of extracts by ethanol extracts of E. japonica leaves are $80 \%$ EtOH $(61.96 \pm 5.01 \mu \mathrm{g} / \mathrm{mL}, 60 \%$ EtOH $(63.87 \pm 0.59 \mu \mathrm{g} / \mathrm{mL})$, $40 \% \operatorname{EtOH}(72.92 \pm 05.22 \mu \mathrm{g} / \mathrm{mL}), 20 \% \operatorname{EtOH}(75.53 \pm 1.14 \mu \mathrm{g} / \mathrm{mL})$, hot water $(102.49 \pm 3.04 \mu \mathrm{g} / \mathrm{mL})$, and $100 \% \mathrm{EtOH}(117.96 \pm 0.88 \mu \mathrm{g} / \mathrm{mL})$, respectively (Figure 2A). This is thought to be a complex action of several compounds extracted according to the intrinsic color and ethanol concentration of E. japonica leaves extract (Kyeoung-Cheol \& Ju-Sung, 2018).

\section{$A B T S$ radical scavenging}

ABTS assay performs the antioxidant activity of decolorization when free radicals generated by reaction with potassium persulfate react with antioxidants to remove free radicals (Park et al., 2016). The $\mathrm{RC}_{50}$ value of ethanolic extracts from E. japonica leaves was highest in $60 \% \mathrm{EtOH}$ at $73.81 \pm 0.16 \mu \mathrm{g} / \mathrm{mL}$, hot water $103.12 \pm 0.67 \mu \mathrm{g} / \mathrm{mL}$, and $100 \% \mathrm{EtOH} 169.78 \pm 0.89 \mu \mathrm{g} / \mathrm{mL}$, respectively (Figure $2 \mathrm{~A}$ ). These results did not show a certain tendency to activity. ABTS radical scavenging activity results showed relatively higher activity than DPPH radical scavenging activity. ABTS is capable of measuring both the hydrophilicity and hydrophobic materials of the radical scavenging activity from the extract sample and thus exhibiting high antioxidant activity (Re et al., 1999; Choi \& Shin, 2015; Lee et al., 2016b).

\subsection{The estimation of Antioxidant activity}

\section{FRAP Reducing power}

The FRAP method is a principle that measures the reduction of trivalent iron to divalent iron by donating electrons directly rather than the radical scavenging assay. It is based on the principle that the ferric tripyridyltriazine (Fe (III) -TPTZ) complex agent is reduced to ferrous tripyridyltriazine (Fe (II) -TPTZ) by antioxidants capacity according to the reduction degree of the sample at a low $\mathrm{pH}$ and it can be said to have a high reducing power when the absorbance value increases as it turns blue (Benzie \& Strain, 1996). FRAP activity of E. japonica leaves extract by ethanol concentration was highest in $60 \%$ ethanol extract $(559.17 \pm 2.69 \mathrm{mg} \mathrm{TE} / \mathrm{g})$ and did not show a significant difference from hot water extract (554.12 $\pm 1.78 \mathrm{mg}$ TE/g). The lowest value of FRAP activity was obtained with $100 \%$ ethanol extract $(317.18 \pm 1.42 \mathrm{mg}$ TE/g) (Figure 2B). These FRAP results showed contrary outcomes to the Kyeoung-Cheol \& Ju-Sung (2018) study that FRAP activity increased as the ethanol content increased. 


\section{Hydrogen peroxide scavenging}

The superoxide dismutase of the human body converts superoxide to hydrogen peroxide, and catalase produces hydrogen peroxide as $\mathrm{H}_{2} \mathrm{O}$. The hydrogen peroxide scavenging activity $\mathrm{RC}_{50}$ value of ethanolic extracts from E. japonica leaves was highest in $60 \% \mathrm{EtOH}$ at $265.33 \pm 3.88 \mu \mathrm{g} / \mathrm{mL}$, followed by $80 \% \mathrm{EtOH}$ $(290.30 \pm 7.08 \mu \mathrm{g} / \mathrm{mL})$, hot water $(290.99 \pm 3.50 \mu \mathrm{g} / \mathrm{mL}), 40 \%$ $\mathrm{EtOH}(299.13 \pm 3.88 \mu \mathrm{g} / \mathrm{mL}), 20 \% \mathrm{EtOH}(314.47 \pm 4.21 \mu \mathrm{g} / \mathrm{mL})$, and $100 \% \mathrm{EtOH}(677.10 \pm 89.23 \mu \mathrm{g} / \mathrm{mL})$, respectively. Any certain tendency to increase the scavenging activity with increasing ethanol content was not confirmed (Figure 2A). It did not show a tendency to increase of scavenging activity with increasing ethanol content.

\section{Nitric oxide radical scavenging}

Nitric oxide (NO) of the active nitrogen species is a highly reactive radical produced from arginine through catalysis of $\mathrm{NO}$ synthase (NOS) enzymes in vivo, and has physiological activities such as blood coagulation, blood pressure control, and immune function against cancer cells (Chung et al., 2001). As a result of measuring the nitric oxide radical scavenging activity value of ethanolic extracts from $E$. japonica leaves, it was confirmed that the scavenging activity increased in concentration-dependent from EtOH extracts. The NO scavenging activity of hot water showed at the concentration of a scavenging activity $31-83 \%$ at $25 \sim 400 \mu \mathrm{g} / \mathrm{mL}$, which was similar to positive control (BHA) of scavenging activity. The $\mathrm{RC}_{50}$ value of ethanolic extracts was highest in hot water at $52.51 \pm 8.54 \mu \mathrm{g} / \mathrm{mL}$, followed by $60 \%$ $\mathrm{EtOH}(59.33 \pm 9.88 \mu \mathrm{g} / \mathrm{mL}), 40 \% \mathrm{EtOH}(5.66 \pm 7.82 \mu \mathrm{g} / \mathrm{mL}), 20 \%$ $\mathrm{EtOH}(75.96 \pm 9.31 \mu \mathrm{g} / \mathrm{mL}), 80 \% \mathrm{EtOH}(106.48 \pm 8.55 \mu \mathrm{g} \mathrm{mL})$, $100 \% \mathrm{EtOH}(154.79 \pm 3.29 \mu \mathrm{g} / \mathrm{mL}$ ), respectively (Figure $2 \mathrm{~A}$ ). This is a different result from that of $80 \% \mathrm{EtOH}$ showing the best scavenging activity in nitric oxide scavenging ability (Lee \& Kim, 2009) because it is considered to be the difference between extraction conditions and methods (Akowuah et al., 2005).

\subsection{Correlation of antioxidant capacity with free radical scavenging}

The correlation of the antioxidant activities with phenolic and flavonoid contents from E. japonica leaves is shown in Table 2. The value of the correlation coefficient ( $r$ ) shows a positive correlation closer to 1 based on 0 , and a negative correlation closer to -1 based on 0 . The correlation between the polyphenol
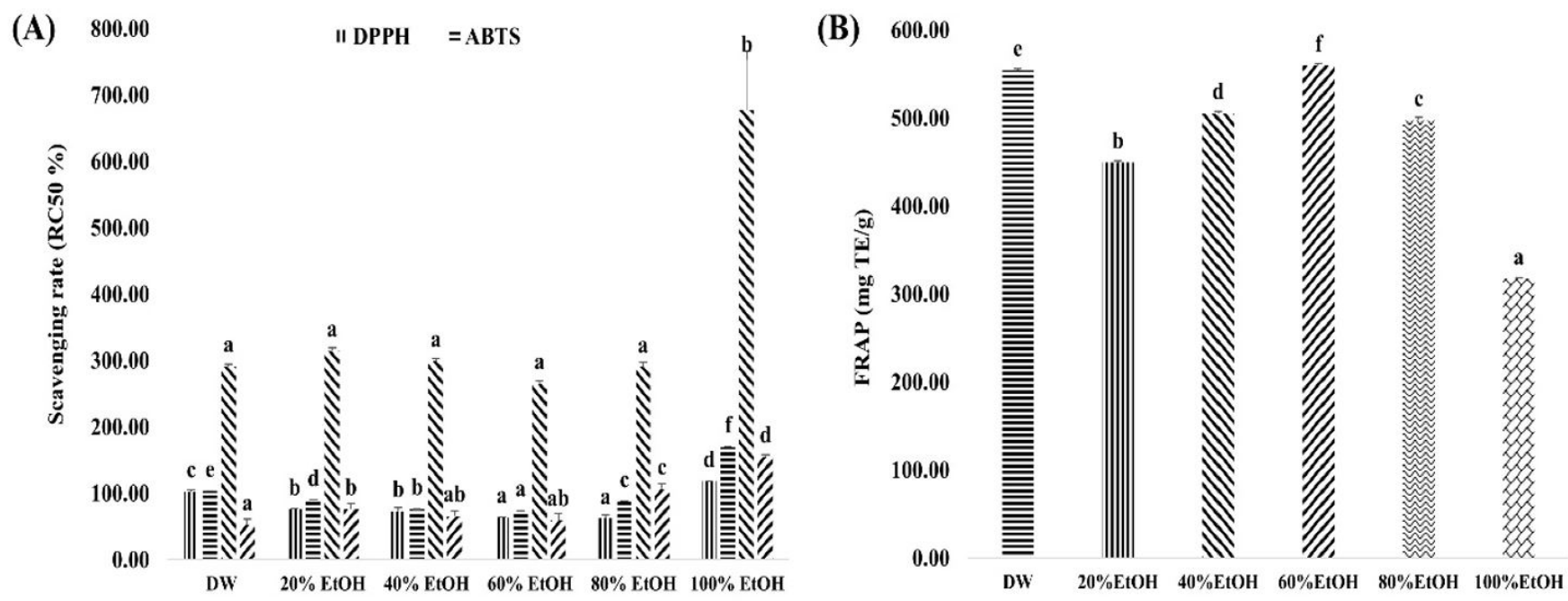

Figure 2. Antioxidant activity of ethanolic extracts from E. japonica Leaves. (A) $\mathrm{RC}_{50}(\mu \mathrm{g} / \mathrm{mL})$ for DPPH, ABTS, HP and NO. Values are means of triplicate determination \pm S.D; (B) FRAP values of ethanol solvent concentration. Means with different letters (a-f) in the same column are significantly different at $\mathrm{p}<0.05$ (Tukey).

Table 2. Correlation coefficients among total polyphenol (TPC), flavonoid contents (TFC), antioxidant activities of E. japonica leaves.

\begin{tabular}{|c|c|c|c|c|c|c|c|}
\hline Factors & TPC & TFC & FRAP & $\mathrm{DPPH}$ & ABTS & HP & $\mathrm{NO}$ \\
\hline TPC & 1 & $0.955^{*+1)}$ & $0.859^{* *}$ & $0.526^{* *}$ & $0.485^{\star *}$ & $0.467^{* *}$ & 0.193 \\
\hline TFC & - & 1 & $0.916^{* *}$ & $0.670^{\star *}$ & $0.654^{\star *}$ & $0.465^{\star *}$ & 0.350 \\
\hline FRAP $^{2)}$ & - & - & 1 & $0.737^{\star *}$ & $0.707^{\star *}$ & $0.450^{*}$ & $0.403^{\left.*_{1}\right)}$ \\
\hline $\mathrm{DPPH}^{3)}$ & - & - & - & 1 & $0.972^{\star *}$ & $0.801^{* *}$ & $0.905^{\star x}$ \\
\hline $\mathrm{ABTS}^{4)}$ & - & - & - & - & 1 & $0.874^{\star *}$ & $0.933^{* x}$ \\
\hline $\mathrm{HP}^{5)}$ & - & - & - & - & - & 1 & $0.777^{\star x}$ \\
\hline $\mathrm{NO}^{6}$ & - & - & - & - & - & - & 1 \\
\hline
\end{tabular}

${ }^{1)}$ Correlation is significantly different at ${ }^{*} \mathrm{p}<0.05$ and ${ }^{* *} \mathrm{p}<0.01$ (Pearson). ${ }^{2)}$ FRAP (Ferric reducing antioxidant power) ${ }^{3)}$ DPPH $(\alpha, \alpha$-diphenyl- $\beta$-picrylhydrazyl) radical scavenging

${ }^{4)}$ ABTS (2,2'-azino-bis(3-ethylbenzothiazoline-6-sulfonic acid)) radical scavenging ${ }^{5)} \mathrm{HP}$ (Hydrogen peroxide) scavenging ${ }^{6)} \mathrm{NO}$ (Nitric oxide) radical scavenging 

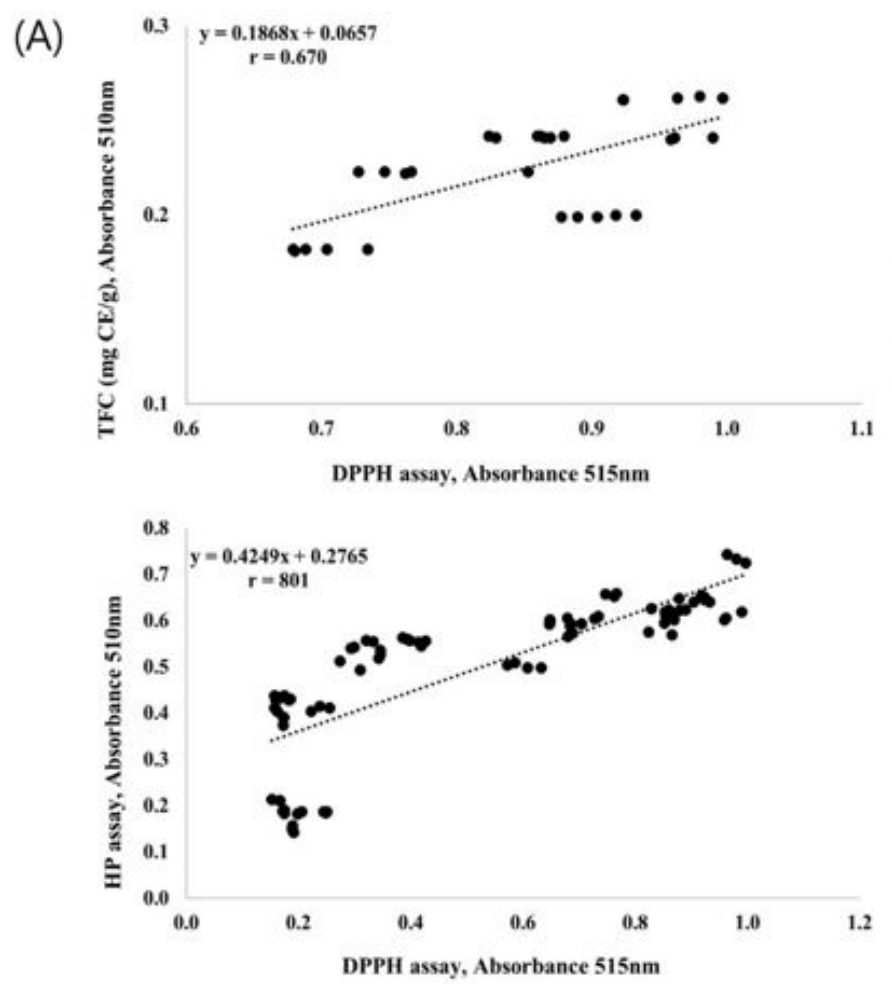

(B)
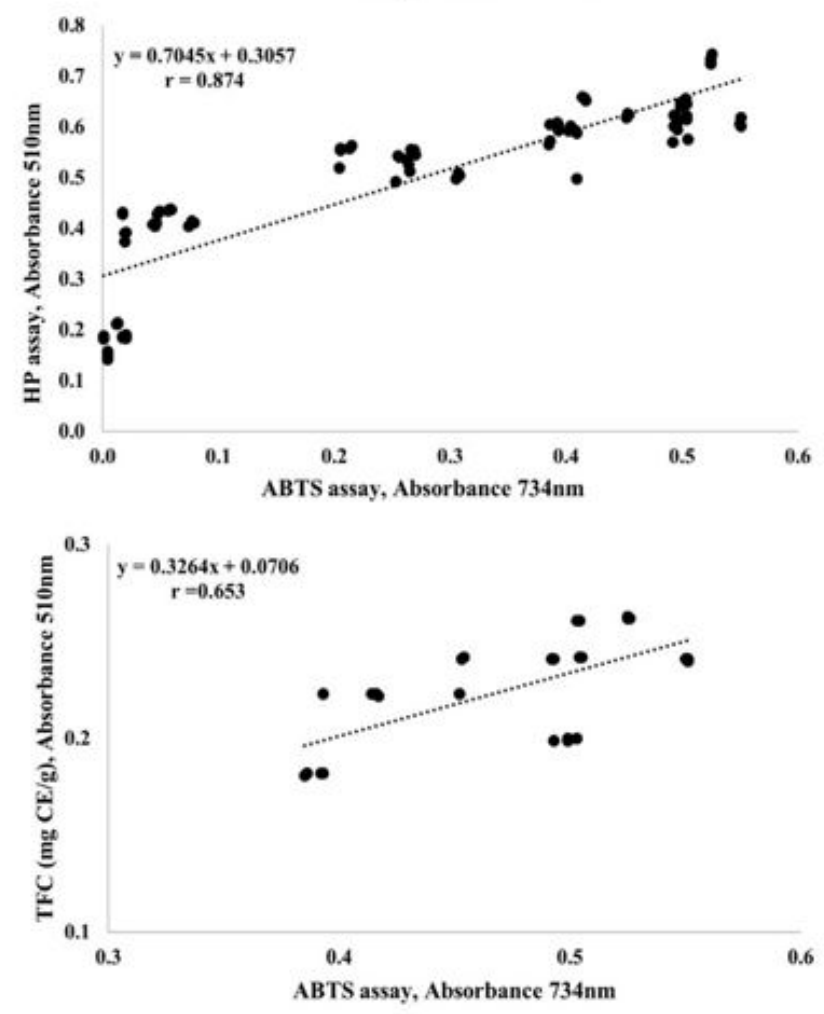
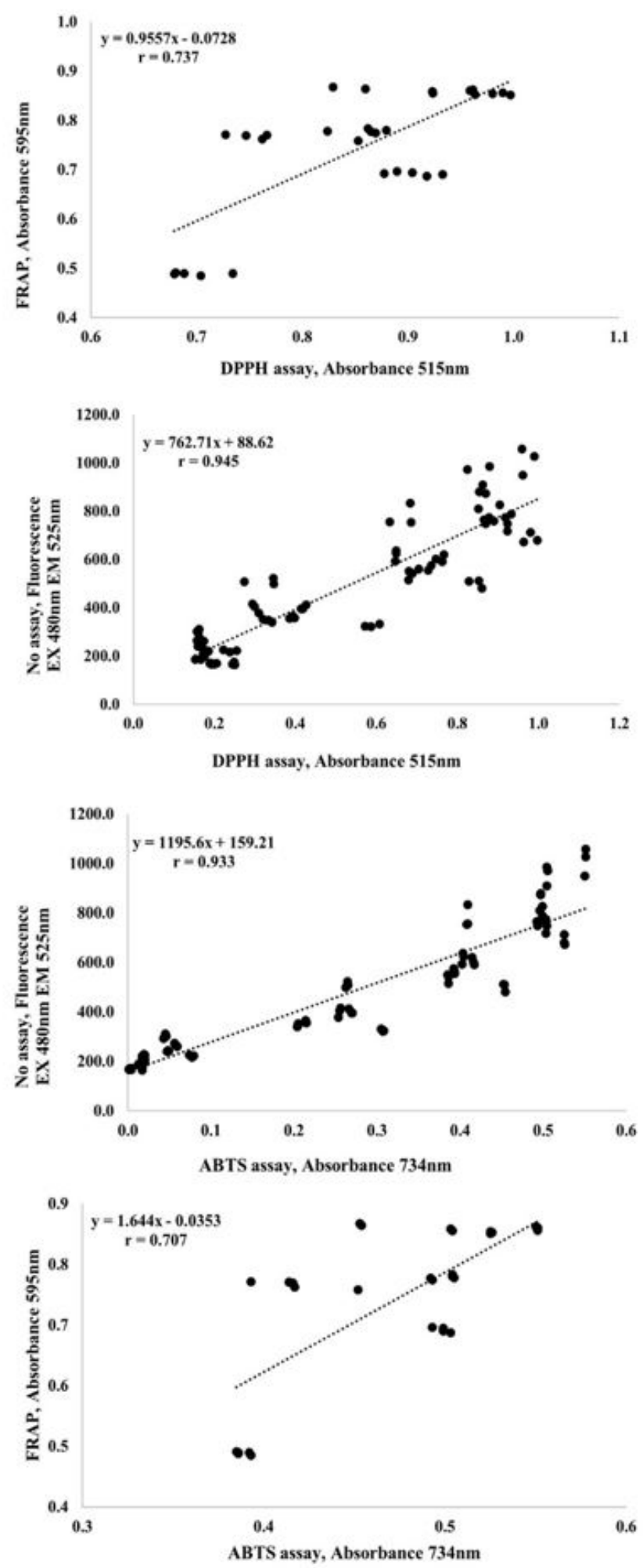

Figure 3. Correlation between free radicals and antioxidant activity of E. japonica Leaves. (A) Correlation between DPPH free radicals, TFC, FRAP, HP and NO, (B) Correlation between ABTS free radicals, TFC, FRAP, HP and NO.

and flavonoid contents of ethanolic extracts $(0.955, \mathrm{p}<0.01)$ showed a significant correlation, and no correlation with nitric oxide. The correlation between DPPH and ABTS confirming the electron donating ability was $0.972(\mathrm{p}<0.01)$, which showed a significant high correlation (Table 2). The correlation of DPPH for TFC, FRAP, HP, and NO showed 0.670, 0.737, 0.801, and $0.905(\mathrm{p}<0.01)$, respectively, and significant correlation was confirmed (Figure $3 \mathrm{~A}$ ). In addition, the correlation of ABTS 
for TFC, FRAP, HP, and NO was measured 0.654 0.707, 0.874, and $0.933(\mathrm{p}<0.01)$, respectively, and significant correlation was confirmed (Figure 3B). Therefore, it is thought that the free radical activity in extracts by ethanol concentration from E. japonica leaves is involved in scavenging activity of reactive oxygen species (ROS) and reactive nitrogen species (RNS). Also, the polyphenol and flavonoid contents of the extract showed a significant correlation with the free radical scavenging ability (DPPH, ABTS) and electron donating ability (FRAP), but does not appear to correlation with the NO scavenging ability.

\section{Conclusions}

The results of this study indicated that the hot water extract of E. japonica leaves owing to high levels of flavonoids and phenols content, showed reductions activity of FRAP, DPPH, ABTS, HP, $\mathrm{NO}$ assay. In the extract of E. japonica leaves, the correlation of the free radical and antioxidant activities with polyphenol and flavonoid contents was showed high significant. Therefore, the phytochemical content of hot water extract from E. japonica leaves revealed potential and economic value because of its use in antioxidant functional food and anti-ageing cosmetics raw materials, as well as in pharmaceuticals. In addition, correlations in the studied antioxidant activities will offer better understanding of post-harvest physiology of E. japonica leaves.

\section{References}

Akowuah, G. A., Ismail, Z., Norhayati, I., \& Sadikun, A. (2005). The effects of different extraction solvents of varying polarities on polyphenols of Orthosiphon stamineus and evaluation of the free radical-scavenging activity. Food Chemistry, 93(2), 311-317. http:// dx.doi.org/10.1016/j.foodchem.2004.09.028.

Bae YI, Chung YC, Shim KH. (2002a). Antimicrobial and antioxidant activities of various solvent extract from different parts of loquat (Eriobotrya japonica Lindl.). Korean Journal Postharvest, 9(1), 97-101.

Bae YI, Jeong CH, Shim KH. (2002b). Nitrite-scavenging and antimutagenic effects of various solvent extract from different parts of loquat (Eriobotrya japonica Lindl.). Korean Journal Postharvest, 9(1), 92-96.

Bae YI, Moon JS and Shim KH. (1998). Loquat (Eriobotrya japonica Lindl.) Juice Processing and Its Physicochemical Properties. Korean Journal Postharvest, 5(3), 270-274.

Benzie, I. F. F., \& Strain, J. J. (1996). The ferric reducing ability of plasma (FRAP) as a measure of "antioxidant power": The FRAP assay. Analytical Biochemistry, 239(1), 70-76. http://dx.doi.org/10.1006/ abio.1996.0292. PMid:8660627.

Blois, M. S. (1958). Antioxidant determinations by the use of a stable free radical. Nature, 181(4617), 1199-1200. http://dx.doi. org/10.1038/1811199a0.

Carr, A. C., McCall, M. R., \& Frei, B. (2000). Oxidation of LDL by myeloperoxidase and reactive nitrogen species: reaction pathways and antioxidant protection. Arteriosclerosis, Thrombosis, and Vascular Biology, 20(7), 1716-1723. http://dx.doi.org/10.1161/01. ATV.20.7.1716. PMid:10894808.

Cho, Y. S., Pakr, S. K., \& Lee, H. Y. (1991). Composition of free sugars, organic acids and free amino acids in loquat flesh. Korean Society of Food and Nutrition, 20, 89-93.

Choi, M. H., \& Shin, H. J. (2015). Anti-oxidative and anti-melnogenesis effects of buleberry extract. Asian Journal of Beauty and Cosmetology, 13(2), 261-266.
Choi, Y. M., Kim, M. H., Shin, J. J., Park, J. M., \& Lee, J. S. (2003). The antioxidant activities of the some commercial teas. Journal of the Korean Society of Food Science and Nutrition, 32(5), 723-727. http:// dx.doi.org/10.3746/jkfn.2003.32.5.723.

Chung, H. T., Pae, H. O., Choi, B. M., Billiar, T. R., \& Kim, Y. M. (2001). Nitric oxide as a bioregulator of apoptosis. Biochemical and Biophysical Research Communications, 282(5), 1075-1079. http:// dx.doi.org/10.1006/bbrc.2001.4670. PMid:11302723.

Chung, H. Y., Soung, D. Y., Kim, A. R., Choi, H. R., Kim, H. J., Choi, J. S., Yang, R., Lee, K. H., \& Yu, B. P. (2000). Generation, toxicity and scavenging of ONOO-: its involvement in the aging process. Journal of Korean Gerontological Nursing, 10, 46-59.

Eom, H. J., Kim, S., Pyo, B. S., \& Lee, K. I. (2009). Changes of physiological activity by drying temperature in leaves of Eriobotrya japonica. The Korean Society of Pharmacognosy, 40(3), 178-183.

Folin, O., \& Denis, W. (1912). On phosphotungastic phosphomolybdic compounds as color regents. The Journal of Biological Chemistry, $12(2), 239-243$.

Halliwell, B., Gutteridge, J. M. C., \& Cross, C. E. (1992). Free radicals, antioxidants and human disease: Where are we now? The Journal of Laboratory and Clinical Medicine, 119(6), 598-620. http://dx.doi. org/10.5555/uri:pii:002221439290284R. PMid:1593209.

Ham, H., Woo, K. S., Lee, B., Park, J., Sim, E., Kim, B. J., Lee, C., Kim, S.-J., Kim, W. H., Lee, J., \& Lee, Y.-Y. (2015). Antioxidant compounds and activities of methanolic extracts from oat cultivars. Journal of the Korean Society of Food Science and Nutrition, 44(11), 1660-1665. http://dx.doi.org/10.3746/jkfn.2015.44.11.1660.

Hwang, E.-S., \& Thi, N. D. (2014). Antioxidant contents and antioxidant activities of hot-water extracts of aronia (Aronia melancocarpa) with different drying methods. Korean Society of Food Science and Technology, 46(3), 303-308. http://dx.doi. org/10.9721/KJFST.2014.46.3.303.

Hwang, Y. G., Lee, J. J., Kim, A. R., \& Lee, M. Y. (2010). Chemical Components and Antioxidative Effects of Eriobotrya japonica Lindl. Leaves. Korean Society of Life Science, 20(11), 1625-1633. http:// dx.doi.org/10.5352/JLS.2010.20.11.1625.

Jeong, Y. S., Jung, H. K., Youn, K. S., Kim, M. O., \& Hong, J. H. (2009). Physiological Activities of the Hot Water Extract from Eriobotrya japonica Lindl. The Korean Society of Food Science and Nutrition, 38(8), 977-982. http://dx.doi.org/10.3746/ jkfn.2009.38.8.977.

Jung, H. A., Park, J. C., Chung, H. Y., Kim, J., \& Choi, J. S. (1999). Antioxidant flavonoids and chlorogenic acid from the leaves of Eriobotrya japonica. Archives of Pharmacal Research, 22(2), 213-218. http://dx.doi.org/10.1007/BF02976549. PMid:10230515.

Kim, J. O., Jung, M. J., Choi, H. J., Lee, J. T., Lim, A. K., Hong, J. H., \& Kim, D. I. (2008). Antioxidative and biological activity of hot water and ethanol extracts from Phellinus linteus. The Korean Society of Food Science and Nutrition, 37(6), 684-690. http://dx.doi. org/10.3746/jkfn.2008.37.6.684.

Kim, Y. D., Mahinda, S., Koh, K.-S., Jeon, Y.-J., \& Kim, S.-H. (2009). Reactive oxygen species scavenging activity of jeju native citrus peel during maturation. The Korean Society of Food Science and Nutrition, 38(4), 462-469. http://dx.doi.org/10.3746/ jkfn.2009.38.4.462.

Kyeoung-Cheol, K., \& Ju-Sung, K. (2018). Effect of ethanol solvent concentration on antioxidant activity of dolwoe (Gynostemma pentaphyllum Makino) leaves extracts. Journal of Advanced Engineering and Technology, 11(3), 197-203. http://dx.doi.org/10.35272/ jaet.2018.11.3.197. 
Lee, B. Y., Park, E. M., Kim, E. J., Choi, H. D., Kim, I. H., \& Hwang, J. B. (1996). Analysis of chemical components of Korean loquat (Eriobotrya japonica Lindl.) fruit. Korean Society of Food Science and Technology, 28(3), 428-432.

Lee, H., Kim, Y. K., Lee, H. J., \& Lee, J. J. (2016a). Effects of loquat (Eriobotrya japonica Lindl.) ethanol extracts of different aerial parts on antioxidant activity and antiproliferation of human cancer cells. The Korean Society of Community Living Science, 27(2), 211-220. http://dx.doi.org/10.7856/kjcls.2016.27.2.211.

Lee, S. H., Jang, M., \& Kim, G. H. (2016b). Antioxidative effects of extracts from different parts of epimedium koreanum nakai. The Korean Society of Food Science and Nutrition, 45(2), 188-193. http:// dx.doi.org/10.3746/jkfn.2016.45.2.188.

Lee, K. I., \& Kim, S. M. (2009). Antioxidative and Antimicrobial Activities of Eriobotrya japonica Lindl. Leaves Extracts. The Korean Society of Food Science and Nutrition, 38(3), 267-273. http://dx.doi. org/10.3746/jkfn.2009.38.3.267.

Liu, R. H. (2004). Potential synergy of phytochemicals in cancer prevention: mechanism of action. The Journal of Nutrition, 134(12, Suppl), 3479S-3485S. http://dx.doi.org/10.1093/jn/134.12.3479S. PMid:15570057.

Manach, C., Williamson, G., Morand, C., Scalbert, A., \& Remesy, C. (2005). Bioavailability and bioefficacy of polyphenols in humans. I. Review of 97 bioavailability studies. The American Journal of Clinical Nutrition, 81(1, Suppl), 230S-242S. http://dx.doi.org/10.1093/ ajcn/81.1.230S. PMid:15640486.

Middleton, E. J., \& Kandaswami, C. (1994). Potential health promoting properties of citrus flavonoids. Food Technology, 48, 115-119.

Muller, H. E. (1995). Detection of hydrogen peroxide produced by microorganism on ABTS peroxidase medium. Zentralblatt für Bakteriologie. Mikrobiologie und Hygiene, 259(2), 151-158. http:// dx.doi.org/10.1016/S0176-6724(85)80045-6.

Nazato, N., Matsumoto, K., \& Uemitsu, N. (1994). Triterpenes from leaves of Eriobotrya japonica. Natural Medicine Note, 48(2), 336-339.

Park SH, Lim HY, Han JH. (2003). A study of medicinal herbs for functional food application-(I) nutritional composition and scolpectin analysis of Artemisia capilaries. The East Asian Society of dietary Life Dietary Life, 13, 552-560.

Park, G., Sim, Y., Lee, W., Sung, S. H., \& Oh, M. S. (2016). Protection on skin aging mediated by antiapoptosis effects of the water lily (Nymphaea tetragona georgi) via reactive oxygen species scavenging in human epidermal keratinocytes. Pharmacology, 97(5-6), 282-293. http://dx.doi.org/10.1159/000444022. PMid:26915077.
Park, Y. S., \& Kim, S. R. (2000). Change in cold injury and fruit quality in loquat fruit as influenced by bloom dates. Han'guk Wonye Hakhoe Chi. Han'guk Wonye Hakhoe, 41(6), 623-626.

Park, Y. S., \& Park, H. S. (1995). Changes in cold injury and contents of chemical compounds as related the different growth stage of immature loquat fruit. Han'guk Wonye Hakhoe Chi. Han'guk Wonye Hakhoe, 36, 522-534.

Park, Y. S., Park, Y. J., Kim, H. J., Im, M. H., Lee, M. K., Kum, Y. M., Cho, J. Y., \& Heo, B. G. (2008). Physiological activity of ethanol extract from the different plant parts of loquat (Eriobotrya japonica Lindl.). Weonye Gwahag Gisulji, 26(1), 75-80.

Re, R., Pellegrini, N., Proteggente, A., Pannala, A., Yang, M., \& RiceEvans, C. (1999). Antioxidant activity applying an improved ABTS radical cation decolorization assay. Free Radical Biology \& Medicine, 26(9-10), 1231-1237. http://dx.doi.org/10.1016/S0891-5849(98)003153. PMid:10381194.

Rittié, L., \& Fisher, G. J. (2002). UV-light-induced signal cascades and skin aging. Ageing Research Reviews, 1(4), 705-720. http://dx.doi. org/10.1016/S1568-1637(02)00024-7. PMid:12208239.

Ryu, S. W., Jin, C. W., Lee, H. S., Lee, J. Y., Sapkota, K., Lee, B. G., Yu, C. Y., Lee, M. K., Kim, M. J., \& Cho, D. H. (2006). Changes in total polyphenol, total flavonoid contents and antioxidant activities of Hibiscus cannabinus L. The Korean Society of Medicinal Crop Science, 14(5), 307-310.

Saleh, E. S., \& Hameed, A. (2008). Total phenolic contents and free radical scavenging activity of certain egyptian Ficus species leaves samples. Food Chemistry, 114(4), 1271-1277. http://dx.doi.org/10.1016/j. foodchem.2008.11.005.

Shin, H. J., Kim, K. H., Hwang, H. R., Kim, N. Y., Kim, S. H., \& Yook, H. S. (2012). Antioxidant activities of extract fractions of leaves from loquat (Eriobotrya japonica Lindl.) by cultivars. The Korean Society of Food Science and Nutrition, 41(8), 1029-1034. http://dx.doi. org/10.3746/jkfn.2012.41.8.1029.

Song, W. Y., Byeon, S. J., \& Choi, J. H. (2015). Anti-oxidative and anti-inflammatory activities of Sasa borealis extracts. Journal Agriculture \& Life Science, 49(3), 145-154. http://dx.doi.org/10.14397/ jals.2015.49.3.145.

Yoo, J. H., Cha, J. Y., Jeong, Y. K., Chung, K. T., \& Cho, Y. S. (2004). Antioxidative effect of pine (Pinus densiflora) needle extracts. Korean Society of Life Science, 14(5), 863-867.

Yu, B. P. (1996). Aging and oxidative stress: modulation by dietary restriction. Free Radical Biology \& Medicine, 21(5), 651-668. http:// dx.doi.org/10.1016/0891-5849(96)00162-1. PMid:8891668. 